\title{
Soft tissue deposits from head and neck cancer: an under-recognised prognostic factor?
}

\begin{abstract}
Introduction
Prognostic factors have considerable influence in the management of cancer, and the quest for a thorough understanding of these elements remains one of the holy grails of surgeons and oncologists. In squamous cell carcinoma of the head and neck, the presence or absence of cervical lymph node metastases at presentation has been identified as the single most important independent factor affecting prognosis. ${ }^{1}$ Overall, the presence of nodal metastasis reduces the five-year survival rate by approximately 50 per cent. ${ }^{2}$ Prognostic factors which have been identified include the size of the largest metastatic deposit within a lymph node, ${ }^{3}$ the number of lymph nodes involved and the location of those lymph nodes (that is, positive level IV and V nodes carry a worse prognosis than higher level nodes). ${ }^{4}$ In the past few years, extracapsular spread has increasingly been recognised as another crucial prognostic factor. Macroscopic and microscopic extracapsular spread adversely affect the outcome in oncological patients. 5
\end{abstract}

The finding of cervical soft tissue tumour deposits, on the other hand, represents a phenomenon which may be tremendously influential prognostically. However, this is a finding which, to date, has been grossly under-reported and unrecognised in clinical studies of head and neck cancer.

\section{Pathophysiology and terminology}

Cancer spreads from a primary site by a process of embolisation or permeation via the lymphatic channels draining the site. Other paths of spread may include the vascular or the perineural routes. Tumour cells travel via lymphatic vessels to reach the cervical lymph nodes. After this, the fate of these cells depends on the local environment, the host immune response and the inherent metastatic potential of the cells. Some of these tumour cells are engulfed or localised by the immune system, while the aggressive ones spread beyond the capsule of the node or to the neighbouring lymph nodes. The immune response of an individual lymph node is often overwhelmed by the tumour cells, whereupon the entire lymph node architecture is replaced by metastatic neoplastic cells.

Alternatively, the tumour cells can make their way out of the lymphatic channels and into the soft tissues of the neck, or embolise via the lymphatic channels themselves, as demonstrated in experimental models. ${ }^{7}$ Later, these emboli can grow and replace the wall of the lymphatic channel. In either of these two scenarios, histopathological examination would show deposits of neoplastic cells in the soft tissues of the neck, with no evidence of lymph node metastasis (Figure 1). These scenarios raise the possibility of a more aggressive nature of tumour spread, when contrasted with those metastases which remain confined to recognisable lymph node structures.

In the literature, there is, to date, a paucity of data that explicitly describe what import - if any - a finding of free soft tissue deposits might have. The term 'soft tissue deposit' is used rather imprecisely and encompasses a host of phenomena, which include direct extension of tumour cells from the primary site into the neck, or even a form of extracapsular spread of tumour from the lymph node into the soft tissues of the neck. Studies of 'soft tissue deposits' have variously defined them as: spread of tumour into pericapsular (extranodal) tissue; ${ }^{8}$ soft tissue spread beyond the lymph node capsule ${ }^{9}$ and extension of tumour through the capsule into the perinodal soft tissue. ${ }^{10}$ Unfortunately, these descriptions lack a precise definition of the exact nature of the soft tissue deposits - that is, whether they represent mere extracapsular spread beyond an obvious original, encompassing lymph node, or whether they are soft tissue deposits apparently separate from nodal involvement. Fagan et al. $^{11}$ (in a report primarily concerning the prognostic significance of perineural invasion in squamous cell carcinoma) described microlymphatic and microvascular invasion, but were unclear whether the presence of actual extravasation of cells into the soft tissues was necessary in order to recognise such cells as soft tissue deposits.

\section{Implication of soft tissue deposits}

Violaris et al. ${ }^{12}$ reviewed the histological slides of 497 patients with head and neck squamous cell carcinoma who had undergone neck dissection. The primary aim of these authors was to confirm the presence or absence of squamous carcinoma within the neck and to ascertain whether any metastases present were to soft tissue, to a lymph node or to both. A deposit was classified as a free soft tissue deposit if (1) there was no apparent continuity with the cells of the primary carcinoma, and (2) there was no discernible organised lymphoid tissue at its peripheral limit. Twenty-eight per cent of their patients had free soft tissue deposits. The survival of patients with soft tissue deposits was significantly reduced when compared with that of patients with ordinary neck node metastases $(p<0.001)$. Violaris 


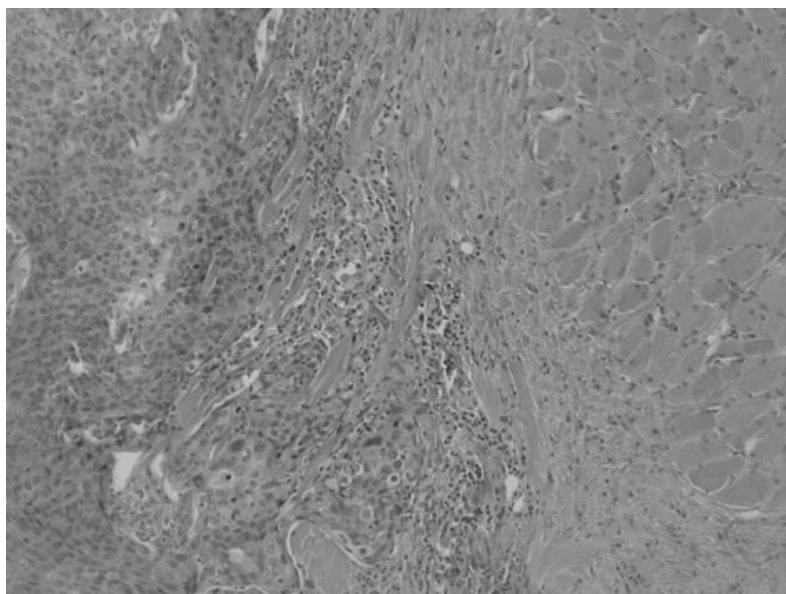

FIG. 1

Photomicrograph demonstrating squamous carcinomatous cells within soft tissues of the neck. Note the absence of lymphoid structure surrounding the neoplastic cells. $(\mathrm{H} \& \mathrm{E} ; \times 200)$

et al. ${ }^{12}$ found soft tissue deposits to be more common in patients with poorly differentiated squamous cell carcinoma, in those with $\mathrm{T}_{4}$ tumours and in those with a poor general state of physical conditioning. Poor general conditioning may reflect the patient's reduced ability to resist the tumour's assault on his or her body; conversely, poor conditioning may just indicate that the patient is already manifesting the effects of the tumour which is going to kill him or her.

Jose et al. ${ }^{13}$ carried out a prospective analysis of both the prevalence and the prognostic implications of soft tissue deposits in 215 neck dissections from 155 patients. Twenty-four per cent of patients had soft tissue deposits in the neck. In a separate report, the authors described the distribution of these soft tissue deposits in the neck specimens; they found that it was similar to lymph node metastasis and that level II was most frequently affected. ${ }^{14}$ The presence of soft tissue deposits had a statistically significant $(p=0.001)$ adverse effect on actuarial and recurrence free survival when compared with patients with $\mathrm{pN}_{0}$ necks, as well as with those with $\mathrm{pN}_{+}$necks without extracapsular spread. There were no differences when patients with soft tissue deposits were compared with patients with $\mathrm{pN}_{+}$ necks with extracapsular spread; this suggests that there is a similar prognostic import for both the presence of extracapsular spread and the presence of soft tissue deposits. Moreover, a finding of soft tissue deposits in $\mathrm{T}_{1}$ tumours may suggest the presence of a particularly aggressive form of disease, with a similar (negative) impact on survival.

\section{Discussion}

The authors consider soft tissue deposits, as defined above, as an additional, significant, independent, adverse prognostic factor that needs to be explored further by researchers when reporting on neck dissections. Consideration of prognostic factors such as the number and level of lymph nodes and the presence of extracapsular spread ${ }^{6}$ has become an established part of mainstream pathology reporting; at present, however, the phenomenon of soft tissue deposits is still an unknown entity. If the presence of soft tissue deposits is indeed a significant prognostic factor, then this has significant implications for the management of head and neck cancer. This is particularly relevant to two aspects of the management of these patients: (1) the techniques used for histopathological reporting of neck dissection specimens, and (2) the selection of minimally invasive procedures, such as sentinel node biopsies, as well as the judicious use of sophisticated laboratory techniques to predict micrometastasis in the neck.

The traditional pathological approach to analysis of cervical lymph node dissection specimens was to search for obviously enlarged lymph nodes $(>2$ or $3 \mathrm{~cm}$ in diameter) by a combination of visual inspection and palpation. These plainly enlarged nodes were then dissected away from the adjacent soft tissue for subsequent light microscopic study. The shortcomings of this technique are obvious - it not only misses smaller lymph nodes that may harbour metastases as well as extracapsular spread (the latter can be present in lymph nodes $3 \mathrm{~mm}$ in diameter), ${ }^{5}$ but it also fails to identify any (small) soft tissue deposits present in the remaining specimen that was to be discarded. This could have clinical relevance, since a relatively high prevalence of these soft tissue deposits has been described, even in patients with clinically $\mathrm{N}_{0}$ necks. ${ }^{15}$

A technique described by one author ${ }^{16}$ involved cutting the entire specimen into $2 \mathrm{~mm}$ thick slices and embedding it in paraffin wax, sectioning it at 6 $\mu \mathrm{m}$ thickness and then staining each section with haematoxylin and eosin for routine light microscopy. Use of this technique would permit identification of areas of microscopic extracapsular spread as well as soft tissue deposits. The additional time and labour involved in carrying out such a sampling technique is believed by some to be justified, in light of the potential value of the additional prognostic information gained.

Neck dissection adds morbidity, and debate continues about its role - particularly in $\mathrm{N}_{0}$ necks. Opinion is divided between advocates of elective neck dissection, those who favour watchful waiting, and those who take the middle ground - that is, those who favour a less invasive procedure (such as sentinel lymph node biopsy) as an intermediary step to guide the selection of a definitive course of action. ${ }^{17}$ The principle underlying each of these approaches revolves around the recognition that occult metastases and micrometastasis in neck nodes exist; therefore, methods of detection need to be devised. It is intuitive to assume that the reason for regional failure might be our inability to detect micrometastasis with conventional histopathological methods - after all, with the advent of immunohistochemical and molecular assays, the sensitivity of detection of smaller and smaller amounts of tumour cells in the neck quadrupled. ${ }^{18}$

While the aforementioned does indeed seem intuitively obvious, it should be noted that early results 
have not disclosed significant differences in survival between patients with $\mathrm{N}_{0}$ necks and those with micrometastases; it remains to be seen whether our ability to detect these micrometastases will confer any benefit in actually doing so. ${ }^{19-22}$

Sentinel node biopsy sampling is also based on the principle of finding (otherwise easily overlooked) micrometastases in the first echelon lymph nodes that drain the primary site. However, as noted previously, such a method will also fail to detect soft tissue deposits in the neck. ${ }^{23,24}$

Recently, Gimm et al. ${ }^{25}$ reported that the presence of disseminated tumour cells in the connective tissue of patients with medullary thyroid carcinoma was correlated with advanced tumour stages, and so appeared to be of prognostic significance. These tumour cells, which may also be termed soft tissue infiltrates, ${ }^{26}$ did not have any apparent connection to the primary tumour or to lymph nodes.

\section{Conclusion}

In summary, we would like to draw attention to the existence of soft tissue tumour deposits in the neck, a phenomenon that has not been well studied in reports of cervical lymph node dissections but which might prove to have prognostic implications similar to those associated with the presence of extracapsular tumour spread. We hope to increase the awareness of this poorly studied phenomenon among pathologists, oncologists and surgeons, and so advocate further research in this regard. Soft tissue tumour deposits should be incorporated into pathological staging systems.

\section{References}

1 Andersen PE, Shah JP, Cambronero E, Spiro RH. The role of comprehensive neck dissection with preservation of the spinal accessory nerve in the clinically positive neck. Am J Surg 1994;168:499-502

2 Moe K, Wolf GT, Fisher SG, Hong WK. Regional metastases in patients with advanced laryngeal cancer. Arch Otolaryngol Head Neck Surg 1996;122:644-8

3 Richard JM, Sancho-Garnier H, Micheau C, Saravane D, Cachin Y. Prognostic factors in cervical lymph node metastasis in upper respiratory and digestive tract carcinomas: study of 1,713 cases during a 15-year period. Laryngoscope 1987;97:97-101

4 Davidson BJ, Kulkarny V, Delacure MD, Shah JP. Posterior triangle metastases of squamous cell carcinoma of the upper aerodigestive tract. Am J Surg 1993;166:395-8

5 Jose J, Coatesworth AP, Johnston C, MacLennan K. Cervical node metastases in squamous cell carcinoma of the upper aerodigestive tract: the significance of extracapsular spread and soft tissue deposits. Head Neck 2003;25:451-6

6 Ferlito A, Rinaldo A, Devaney KO, MacLennan K, Myers JN, Petruzzelli GJ et al. Prognostic significance of microscopic and macroscopic extracapsular spread from metastatic tumor in the cervical lymph nodes. Oral Oncol 2002;38:747-51

7 Cabanillas R, Secades P, Rodrigo JP, Astudillo A, Suárez $\mathrm{C}$, Chiara MD. [Orthotopic murine model of head and neck squamous cell carcinoma]. Acta Otorrinolaringol Esp 2005;56:89-95 [in Spanish]

8 Noone RB, Bonner H Jr, Raymond S, Brown AS, Graham WP 3rd, Lehr HB. Lymph node metastases in oral carcinoma. A correlation of histopathology with survival. Plast Reconstr Surg 1974;53:158-66

9 Kalnins IK, Leonard AG, Sako K, Pazack MS, Shedd DP. Correlation between prognosis and degree of lymph node involvement in carcinoma of the oral cavity. Am J Surg 1977;134:450-4

10 Shingaki S, Nomura T, Takada M, Kobayashi T, Suzuki I, Nakajima T. The impact of extranodal spread of lymph node metastases in patients with oral cancer. Int J Oral Maxillofac Surg 1999;28:279-84

11 Fagan JJ, Collins B, Barnes L, D'Amico F, Myers EN, Johnson JT. Perineural invasion in squamous cell carcinoma of the head and neck. Arch Otolaryngol Head Neck Surg 1998;124:637-40

12 Violaris NS, O'Neil D, Helliwell TR, Caslin AW, Roland NJ, Jones AS. Soft tissue cervical metastases of squamous carcinoma of the head and neck. Clin Otolaryngol 1994;19: 394-9

13 Jose J, Moor JW, Coatesworth AP, Johnston C, MacLennan K. Soft tissue deposits in neck dissections of patients with head and neck squamous cell carcinoma: prospective analysis of prevalence, survival and its implications. Arch Otolaryngol Head Neck Surg 2004;130: $157-60$

14 Moor JW, Jose J, Johnston C, Coatesworth AP, MacLennan KA. Upper aerodigestive tract squamous cell carcinoma: distribution of extracapsular spread and soft tissue deposits in the neck. Acta Otolaryngol 2004;124 97-101

15 Coatesworth AP, MacLennan K. Squamous cell carcinoma of the upper aerodigestive tract: the prevalence of microscopic extracapsular spread and soft tissue deposits in the clinically N0 neck. Head Neck 2002;24:258-61

16 Jose J, Coatesworth AP, MacLennan K. Cervical metastases in upper aerodigestive tract squamous cell carcinoma: histopathologic analysis and reporting. Head Neck 2003;25: 194-7

17 Wei WI, Ferlito A, Rinaldo A, Gourin CG, Lowry J, Ho WK et al. Management of the N0 neck - reference or preference Oral Oncol 2006:42:115-22

18 Elsheikh MN, Rinaldo A, Hamakawa H, Mahfouz ME, Rodrigo JP, Brennan J et al. Importance of molecular analysis in detecting cervical lymph node metastasis in head and neck squamous cell carcinoma. Head Neck 2006;28:842-9

19 Woolgar JA. Micrometastasis in oral/oropharyngeal squamous cell carcinoma: incidence, histopathological features and clinical implications. Br J Oral Maxillofac Surg 1999; 37:181-6

20 Ferlito A, Partridge M, Brennan J, Hamakawa H. Lymph node micrometastases in head and neck cancer: a review. Acta Otolaryngol 2001:121:660-5

21 Devaney SL, Ferlito A, Rinaldo A, Devaney KO. Pathologic detection of occult metastases in regional lymph nodes in patients with head and neck cancer. Acta Otolaryngol 2000;120:344-9

22 Devaney KO, Rinaldo A, Ferlito A. Micrometastases in cervical lymph nodes from patients with squamous carcinoma of the head and neck: should they be actively sought? Maybe. Am J Otolaryngol 2007;28:271-4

23 MacLennan K, Jose J, Ferlito A, Devaney KO, Robbins $\mathrm{KT}$, Moor $\mathrm{J}$ et al. Cervical soft tissue metastases in head and neck cancer. Acta Otolaryngol 2003;123:336-9

24 Devaney KO, Rinaldo A, Rodrigo JP, Ferlito A. Sentinel node biopsy and head and neck tumors - where do we stand today? Head Neck 2006;28:1122-31

25 Gimm O, Heyn V, Krause U, Sekulla C, Ukkat J, Dralle H. Prognostic significance of disseminated tumor cells in the connective tissue of patients with medullary thyroid carcinoma. World J Surg 2006;30:847-52

26 Machens A, Hinze R, Lautenschlager C, Thomusch O, Dralle H. Prophylactic completion thyroidectomy for differentiated thyroid carcinoma: prediction of extrathyroidal soft tissue infiltrates. Thyroid 2001;11:381-4

JEMY JOSE

ALFIO FERLITO

JUAN PABLO RODRIGO

KENNETH O. DEVANEY

ALESSANDRA RINALDO KEN MACLENNAN 